\section{Aqueous humor pentraxin-3 levels in patients with diabetes mellitus}

\author{
Abstract \\ Purpose To evaluate aqueous humor (AH) \\ pentraxin-3 (PTX3) levels in diabetic \\ patients with and without diabetic \\ retinopathy (DR). \\ Methods In this prospective study, patients \\ undergoing cataract surgery were enrolled. \\ The study group was composed of 26 type- 2 \\ diabetic patients without DR (group 1), \\ 32 diabetic patients with DR (group 2) and \\ 29 age-matched subjects without any \\ systemic disease (group 3). Fifteen \\ proliferative DR (PDR) and 17 non- \\ proliferative DR (NPDR) patients were \\ enrolled in Group 2. HbA1c levels and \\ duration of diabetes were noted. AH samples \\ were obtained from anterior chamber at the \\ beginning of cataract surgery and PTX3 levels \\ were analyzed with Elisa kit. \\ Results Baseline demographic characteristics \\ were similar between groups. The mean \\ duration of diabetes was $11.9 \pm 7.9$ years \\ in group 1 and $15.8 \pm 7.8$ years in group 2 \\ $(P=0.11)$. The mean plasma HbA1c levels \\ in group 1 was $9.1 \pm 2.6$ and $8.2 \pm 2.4$ in group \\ $2(P=0.36)$. PTX3 levels were $5.75 \pm 0.41$ \\ in group $1,6.11 \pm 1.47$ in group 2 and \\ $4.93 \pm 0.84 \mathrm{ng} / \mathrm{ml}$ in group $3(P=0.01)$. \\ PTX3 levels in group 2 were higher than in \\ group 1 and $3(P=0.06$ and $P=0.01$, \\ respectively). There was no correlation \\ between HbA1c and PTX3 levels $(P=0.06$ \\ $r=0.57, P=0.19 r=0.3$, respectively). \\ The mean PTX3 was $6.6 \pm 0.3$ in PDR \\ group and $5.6 \pm 0.5 \mathrm{ng} / \mathrm{ml}$ in NPDR group \\ $(P=0.04)$. \\ Conclusions PTX3 is an important marker \\ especially for vascular endothelial damage. \\ Since diabetic vascular changes are \\ dependent on endothelial cell damage, high \\ levels of AH PTX3 of DR patients may \\ indicate the importance of PTX3 protein in \\ the pathogenesis of DR. \\ Eye (2017) 31, 1463-1467; doi:10.1038/eye.2017.87; \\ published online 2 June 2017
}

M Mutlu', N Yuksel'1 , T Takmaz¹ , AS Dincel ${ }^{2}$, A Bilgihan ${ }^{2}$ and $\mathrm{H}$ Altınkaynak ${ }^{1}$

\section{Introduction}

The prevalence of diabetes mellitus (DM) is increasing worldwide and becoming a global health problem. ${ }^{1}$ One of the microvascular complication of DM is diabetic retinopathy (DR), which can be a vision threatening complication. The pathogenesis of DR is still under investigation. Recent studies are especially based on the role of ocular and systemic inflammation in the DR development. Hyperglycemia-induced vascular damage is the initial mechanism of the retinopathy. ${ }^{2}$ Vascular endothelial injury and permeability alteration trigger the inflammatory process. $^{3}$ Increased levels of inflammatory cytokines and proteins in the vitreous, ${ }^{4}$ tear, ${ }^{5}$ aqueous humor, ${ }^{6}$ and plasma samples ${ }^{7}$ of the DR patients have been shown in previous studies.

Pentraxin protein superfamily is composed of acute phase proteins; C-reactive protein (CRP), serum amyloid protein (SAP), and pentraxin-3 (PTX3). Unlike hepatic production of CRP and SAP, PTX3 is synthesized by several peripheral tissues. ${ }^{8,9}$ It has been suggested that PTX3 expression is increased under the conditions of vascular endothelial dysfunction. ${ }^{10,11}$

Microvascular damage in DR and ocular inflammation are related reciprocally.

Inflammatory status in DR patients has been supported by increased serum CRP and high sensitive CRP (hsCRP) levels. ${ }^{12,13}$ In addition, the level of aqueous humor inflammatory cytokines and their correlation with DR development, severity and prognosis has been reported. ${ }^{14}$

Accordingly, the aim of the present study was to evaluate the relationship between aqueous PTX3 level and DR pathogenesis and progression.

Materials and methods

Subjects

This prospective study was approved by the local institutional ethics committee. Informed

\author{
'Department of \\ Ophthalmology, Ankara \\ Ataturk Education and \\ Research Hospital, Ankara, \\ Turkey \\ ${ }^{2}$ Gazi University, Faculty of \\ Medicine, Department of \\ Medical Biochemistry, \\ Ankara, Turkey \\ Correspondence: \\ M Mutlu, Department of \\ Ophthalmology, Ankara \\ Ataturk Education and \\ Research Hospital, \\ Sogutozu Mah. 2185. Sok. \\ Sogutozu Konutları no:9 \\ Sogutozu, Ankara 06000, \\ Turkey \\ Tel: +90 533301 1989; \\ Fax: +90 3122912726 . \\ E-mail: melekmutlu06@ \\ gmail.com
}

Received: 12 December 2016

Accepted in revised form: 2 April 2017 Published online: 2 June 2017 
consent was obtained from all participants before cataract surgery. Patients undergoing cataract surgery in Ataturk Training and Research Hospital between December 2015 and June 2016 were enrolled in the study. We obtained AH samples from 26 type-2 diabetic patients without DR (group 1), 32 type-2 diabetic patients with DR (group 2) and 29 age-sex matched controls (group 3). Group 2 was composed of 15 patients with proliferative DR (PDR) and 17 patients with non-proliferative DR (NPDR). Before cataract surgery all participants had detailed ocular examination. The severity of DR was graded according to the modified Early Treatment Diabetic Retinopathy Study (ETDRS) retinopathy severity scale. ${ }^{15,16}$ Patients with glaucoma, pseudoexfoliation, active ocular inflammation, history of ocular surgery and any retinal pathologies rather than DR were excluded. Other ocular exclusion criteria for DR group were having previous intravitreal corticosteroid or anti vascular endothelial growth factor (anti-VEGF) injections and argon laser focal, grid or panretinal photocoagulation within last 6 months. The stage of DR, duration of DM and serum HbA1c levels were noted. Preoperative systemic examination and routine blood tests including $\mathrm{HbA} 1 \mathrm{c}$ level were performed for all participants within 1 week before cataract surgery. Group 3, as control group, had no systemic or ocular disease apart from cataract.

Cerebrovascular or cardiovascular disease, chronic renal or hepatic failure, autoimmune disease, malignancy, uncontrolled hypertension presence were systemic exclusion criteria for the study groups.

\section{Sample collection and measurements for PTX3}

Undiluted AH samples were collected at the beginning of phacoemulsification surgery through anterior chamber paracentesis with a $27 \mathrm{G}$ needle of tuberculin injector. After collection of $0.1-0.2 \mathrm{ml}$ of $\mathrm{AH}$, samples were immediately transported and frozen at $-80^{\circ} \mathrm{C}$ until biochemical analysis.

The concentration of PTX3 was measured by kit for human PTX3 (R\&D Systems, Inc., Minneapolis, MN, USA) using sandwich ELISA method and measurements were blinded to patient's status. The assay was conducted based on the manufacturer's instructions.

\section{Statistical analysis}

All statistical analysis was performed using SPSS software for Windows version 20.0 (Chicago, IL, USA). The normality of the data was confirmed using the ShappiroWilk test. Results were given as a mean \pm standard error. One-way variance analysis (ANOVA) followed Tukey's post hoc test was used to determine the statistical significance of the comparisons between groups. The correlation between variables was evaluated by Pearson correlation test. A $P$-value less than 0.05 was assumed to be statistically significant.

\section{Results}

Demographical characteristics were shown in Table 1. The mean age was $75.1 \pm 9.5$ in group $1,65.6 \pm 7.2$ in group 2 and $63.6 \pm 11.9$ in group $3(P=0.26)$. There was no significant difference between groups in terms of gender $(P=0.61)$. Duration of DM in group 1 was $11.9 \pm 7.9$ years and $15.8 \pm 7.8$ years in group $2(P=0.11)$. Serum $\mathrm{HbA} 1 \mathrm{c}$ levels were $9.1 \pm 2.6$ in group 1 and $8.2 \pm 2.4$ in group 2 $(P=0.36$; Table 2).

The mean PTX3 levels were $5.75 \pm 0.41$ (5.09-8.65) in group $1,6.11 \pm 1.47$ (4.93-9.57) in group 2 and $4.93 \pm 0.84$ (4.01-6.78) $\mathrm{ng} / \mathrm{mL}$ in group 3 (Figure 1). The difference in PTX3 levels between three groups was statistically significant by using ANOVA test $(P=0.01)$. In DR group, the mean PTX3 level was significantly higher than in control group $(P=0.01)$. The mean PTX3 level of diabetic patients without DR was lower than that in DR group, whereas higher than that in control group ( $P=0.06, P=0.78$, respectively). Two group comparisons (group 1 vs 2 and 1 vs 3) did not show any significant difference by post hoc analysis of Tukey's method.

The mean PTX3 levels in NPDR cases ( $n=17$ eyes) was $5.6 \pm 0.5$, in PDR cases ( $n=15$ eyes) $6.6 \pm 0.3 \mathrm{ng} / \mathrm{ml}$ which was significantly higher $(P=0.04)$.

There was no significant correlation between serum $\mathrm{HbA} 1 \mathrm{c}$ and PTX3 levels in both group 1 and $2(P=0.06$, $r=0.57 / P=0.19, \mathrm{r}=0.3$, respectively).

\section{Discussion}

There is an increasing trend in evaluating different inflammatory molecules in the pathogenesis of DR.

Table 1 Demographics of the groups

\begin{tabular}{lccc}
\hline & $\begin{array}{c}\text { Group 1 (non DR) } \\
\mathrm{n}=26\end{array}$ & $\begin{array}{c}\text { Group 2 (DR) } \\
\mathrm{n}=32\end{array}$ & $\begin{array}{c}\text { Group 3 (non DM) } \\
\mathrm{n}=29\end{array}$ \\
\hline Gender & & & \\
$\quad$ Female/male & $14 / 12$ & $16 / 16$ & $16 / 13$ \\
Age (mean \pm SD, range) & $75.1 \pm 9.5(45-86)$ & $65.6 \pm 7.2(56-83)$ & $63.6 \pm 11.9(29-77)$ \\
\hline
\end{tabular}

Abbreviations: DR, diabetic retinopathy; DM, diabetes mellitus; $n$, number of patients. 
Table 2 Mean $\mathrm{HbA1c}$ level and duration of DM

\begin{tabular}{|c|c|c|c|}
\hline & $\begin{array}{c}\text { Group } 1 \text { (non } D R \text { ) } \\
\mathrm{n}=26\end{array}$ & $\begin{array}{c}\text { Group } 2 \text { (DR) } \\
\mathrm{n}=32\end{array}$ & P-value \\
\hline $\mathrm{HbA1c}($ mean $\pm \mathrm{SD}$, range) & $9.1 \pm 2.6(5.5-13.2)$ & $8.2 \pm 2.4(4.7-13.6)$ & 0.36 \\
\hline Duration of $\mathrm{DM}$ (years, mean $\pm \mathrm{SD}$, range) & $11.9 \pm 7.9(2-25)$ & $15.8 \pm 7.8(3-30)$ & 0.11 \\
\hline
\end{tabular}

Abbreviations: DR, diabetic retinopathy; DM, diabetes mellitus; $n$, number of patients.

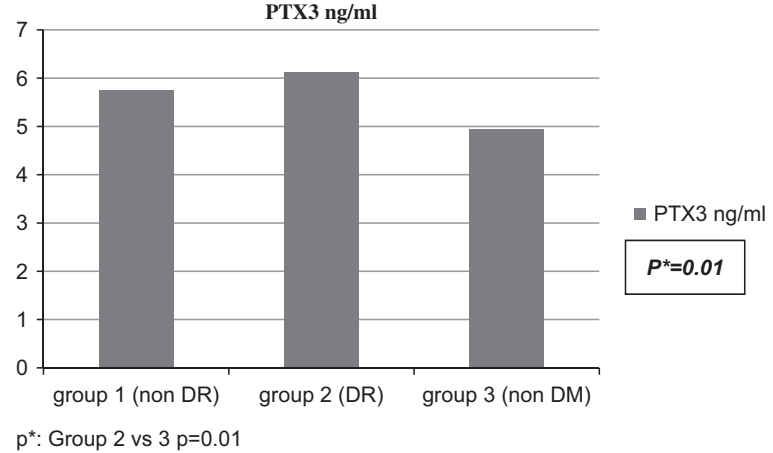

Figure 1 Aqueous humor PTX3 levels. $P^{*}$ : Group 2 vs $3 P=0.01$.

Recent studies in DR have demonstrated the inflammatory basis of the disease via serum or ocular fluid inflammatory cytokine levels. Elevated serum interleukin-1 beta (IL-1 $\beta$ ), tumor necrosis factor-alpha (TNF- $\alpha)$, VEGF, IL-8 levels and their correlation with retinopathy severity have been identified by clinical studies. ${ }^{17-19}$ IL-6, IL-8, IL-10, IL-13, VEGF and monocyte chemoattractant protein-1 (MCP-1) are some of the studied local factors measured from vitreous or aqueous samples related with progression of DR. ${ }^{20-23}$ These inflammatory biomarkers have a crucial role in DR pathogenesis and treatment modalities.

Pentraxin protein superfamily is composed of structurally different acute phase proteins; C-reactive protein (CRP) is classical short pentraxin whereas PTX3 is a member of long pentraxin family. 8,9 The synthesis of PTX3 protein is induced by IL-1 or TNF- $\alpha^{24,25}$ and released by several cell types such as endothelial cells, fibroblasts, mononuclear phagocytes in response to inflammatory circumstances. ${ }^{26,27}$ Woo et al ${ }^{28}$ reported that human retinal pigment epithelial cells may be a major source of PTX3 production in the presence of proinflammatory cytokines IL- 1 and TNF- $\alpha$ according to their cell culture study. Therefore PTX3 could be a novel protein for inflammatory response in the retinal pathologies.

Serum levels of proteins, cytokines and chemokines reflecting inflammatory status may be affected by many systemic conditions and this lead to conflicting results in the literature. For instance, while some studies showed increased serum CRP levels in $\mathrm{DR}^{12,13}$ others showed no significant or inverse relation between CRP and DR. ${ }^{29-31}$
Therefore $\mathrm{AH}$ and vitreous sampling seem to be better option for close reflection of retinal pathological changes. Both samples can be obtained during cataract or retinal surgeries. Generally pars plana vitrectomy (PPV) is not indicated in patients with non-PDR. Vitreous sampling through PPV has some risks like retinal tears or vitreous hemorrhage. In addition, significant relationship between the levels of cytokines from aqueous and vitreous samples has been shown by Funatsu et al. ${ }^{32}$

As an acute phase-reactant PTX3 has a key role in leukocyte recruitment during the inflammatory process. ${ }^{33}$ This leukocyte-endothelial interactions lead to vascular permeability increment as seen in DR. Yang et al ${ }^{34}$ have reported elevated levels of plasma PTX3 in patients with DR and its positive association with DR severity. In the same study they suggested that, the correlation between DR severity and plasma high sensitive CRP (hsCRP) levels were not significant. To the best of our knowledge, this is the first study to show AH PTX3 levels in diabetic patients.

In the current study we compared the $\mathrm{AH}$ levels of PTX3 protein between diabetic patients with and without retinopathy. The level of PTX3 in DR was significantly higher than in control group. Patients with PDR had the highest levels of PTX3 among the cases. This may indicate the importance of PTX3 in pathogenesis as well as in progression of DR. Although diabetic patients without retinopathy had higher PTX3 levels than control patients, the difference was not statistically significant. It may indicate that endothelial cell damage is not significant in the earlier phases of diabetes when DR was not manifest. $\mathrm{DM}$ duration and serum $\mathrm{HbA} 1 \mathrm{c}$ levels were statistically similar among diabetic patients. Although systemic status of diabetes were similar, local PTX3 level difference might have a critical role in retinopathy pathogenesis.

According to our study there was no correlation between $\mathrm{HbA} 1 \mathrm{c}$ and PTX3 levels. However, serum ${ }^{35}$ and vitreous $^{36,37}$ levels of inflammatory markers were found positively correlated with the serum $\mathrm{HbA} 1 \mathrm{c}$ levels in some studies. In our study this correlation was absent. It might be because of small sample size or local production of PTX3 protein might be independent of current diabetic control.

One of the limitations of our study is the lack of serum samples of the study groups. Serum and AH PTX3 levels correlation could have been done in order to demonstrate 
the presence of relationship between systemic and local levels of PTX3. But at the same time it has been shown that diabetic vascular complications apart from DR also affect the serum levels of PTX3 protein. ${ }^{38-40}$ Another limitation of our study was its relatively small sample size. It was because of PTX3 levels might be affected by several systemic diseases such as cardiovascular or cerebrovascular diseases, chronic kidney and liver failure, autoimmune disorders, irregular systemic hypertension. For this reason we could include a limited number of patients.

In conclusion, significantly increased AH levels of PTX3 in DR patients indicate its importance in DR pathogenesis. Further prospective studies with a larger number of participants will be needed to confirm our results moreover, to clarify its benefit as a prognostic biomarker.

\section{Summary}

What was known before

- PTX3 synthesis is increased in the vascular endothelial damage PTX3 serum levels are high in diabetic patients.

What this study adds

- Aqueous humor PTX3 levels are high in patients with DR.

\section{Conflict of interest}

The authors declare no conflict of interest.

\section{Acknowledgements}

This project was supported by Ankara Office of the Turkish Ophthalmology Association.

\section{References}

1 Wild S, Roglic G, Green A, Sicree R, King H. Global prevalence of diabetes: estimates for the year 2000 and projections for 2030. Diabetes Care 2004; 27: 1047-1053.

2 Qian H, Ripps H. Neurovascular interaction and the pathophysiology of diabetic retinopathy. Exp Diabetes Res 2011; 2011: 693426.

3 Tang J, Kern TS. Inflammation in diabetic retinopathy. Prog Retin Eye Res 2011; 30: 343-358.

4 Kovacs K, Marra KV, Yu G, Wagley S, Ma J, Teague GC et al. Angiogenic and inflammatory vitreous biomarkers associated with increasing levels of retinal ischemia. Invest Ophthalmol Vis Sci 2015; 56: 6523-6530.

5 Liu J, Shi B, He S, Yao X, Willcox MD, Zhao Z. Changes to tear cytokines of type 3 diabetic patients with or without retinopathy. Mol Vis 2010; 16: 2931-2938.

6 Cheung CM, Vania M, Ang M, Chee SP, Li J. Comparison of aqueous humor cytokine and chemokine levels in diabetic patients with and without retinopathy. Mol Vis 2012; 18: 830-837.

7 Yuuk T, Kanda T, Kimura Y, Kotajima N, Tamura J, Kobayashi I et al. Inflammatory cytokines in vireous flid and serum of patients with diabetic vitreoretinopathy. J Diabetes Complications 2001; 15: 257-259.

8 Alles VV, Bottazzi B, Peri G, Golay J, Introna M, Mantovani A. Inducible expression of PTX3, a new member of the pentraxin family, in human mononuclear phagocytes. Blood 1994; 84: 3483-3493.

9 Manfredi AA, Rovere-Querini P, Bottazzi B, Garlanda C, Mantovani A. Pentraxins, humoral innate immunity and tissue injury. Curr Opin Immunol 2008; 20: 538-544.

10 Cieślik P, Hrycek A. Long pentraxin 3 (PTX3) in the light of its structure, mechanism of action and clinical implications. Autoimmunity 2012; 45: 119-128.

11 Deban L, Russo RC, Sironi M, Moalli F, Scanziani M, Zambelli $\mathrm{V}$ et al. Regulation of leukocyte recruitment by the long pentraxin PTX3. Nat Immunol 2010; 11: 328-334.

12 Muni RH, Kohly RP, Lee EQ, Manson JE, Semba RD, Schaumberg DA. Prospective study of inflammatory biomarkers and risk of diabetic retinopathy in the diabetes control and complications trial. JAMA Ophthalmol 2013; 131: 514-521.

13 Kocabora MS, Telli ME, Fazil K, Erdur SK, Ozsutcu M, Cekic $\mathrm{O}$ et al. Serum and Aqueous Concentrations of Inflammatory Markers in Diabetic Macular Edema. Ocul Immunol Inflamm 2016; 24: 549-554.

14 Dong N, Xu B, Wang B, Chu L. Study of 27 aqueous humor cytokines in patients with type 2 diabetes with or without retinopathy. Mol Vis 2013; 19: 1734-1746.

15 Early Treatment Diabetic Retinopathy Study Research Group (1991). Grading diabetic retinopathy from stereoscopic color fundus photographs. An extension of the modified Airlie House classification. ETDRS Report Number 10. Ophthalmology 1991; 98(5 Suppl): 786-806.

16 Early Treatment Diabetic Retinopathy Study Research Group (1991). Fundus photographic risk factors for progression of diabetic retinopathy. ETDRS Report Number 12. Ophthalmology 1991; 98(5 Suppl): 823-833.

17 Kaul K, Hodgkinson A, Tarr JM, Kohner EM, Chibber R. Is inflammation a common retinal-renal-nerve pathogenic link in diabetes? Curr Diabetes Rev 2010; 6: 294-303.

18 Ozturk BT, Bozkurt B, Kerimoglu H, Okka M, Kamis U, Gunduz K. Effect of serum cytokines and VEGF levels on diabetic retinopathy and macular thickness. Mol Vis 2009; 15: 1906-1914.

19 Doganay S, Evereklioglu C, Er H, Türköz Y, Sevinç A, Mehmet $\mathrm{N}$ et al. Comparison of serum NO, TNF-alpha, IL-1beta, sIL-2R, IL-6 and IL-8 levels with grades of retinopathy in patients with diabetes mellitus. Eye (Lond) 2002; 16: 163-170.

20 Suzuki Y, Nakazawa M, Suzuki K, Yamazaki H, Miyagawa Y. Expression profiles of cytokines and chemokines in vitreous fluid in diabetic retinopathy and central retinal vein occlusion. Jpn J Ophthalmol 2011; 55: 256-263.

21 Petrovic MG, Korošec P, Košnik M, Hawlina M. Association of preoperative vitreous IL- 8 and VEGF levels with visual acuity after vitrectomy in proliferative diabetic retinopathy. Acta Ophthalmol 2010; 88: e311-e316.

22 Yoshimura T, Sonoda KH, Sugahara M, Mochizuki Y, Enaida H, Oshima Y et al. Comprehensive analysis of inflammatory immune mediators in vitreoretinal diseases. PLOS ONE 2009; 4: e8158. 
23 Oh IK, Kim SW, Oh J, Lee TS, Huh K. Inflammatory and angiogenic factors in the aqueous humor and the relationship to diabetic retinopathy. Curr Eye Res 2010; 35: 1116-1127.

24 Lee GW, Lee TH, Vilcek J. TSG-14, a TNF- and IL-1 inducible protein, is a novel member of the pentraxin family of acute phase proteins. J Immunol 1993; 150: 1804-1812.

25 Breviario F, D'Aniello EM, Golay J, Peri G, Bottazzi B, Bairoch A et al. IL-1-inducible genes in endothelial cells: cloning of a new gene related to C-reactive protein and serum amyloid P component. J Biol Chem 1992; 267: 22190-22197.

26 Alles VV, Bottazzi B, Peri G, Golay J, Introna M, Mantovani A. Inducible expression oof PTX3, a new member of the pentraxin family, in human mononuclear phagocytes. Blood 1994; 84: 3483-3493.

27 Garlanda C, Bottazzi B, Bastone A, Mantovani A. Pentarxins at the crossroads between innate immunity, inflammation, matrix deposition and female fertility. Annu Rev Immunol 2005; 23: 337-366.

28 Woo JM, Kwon MY, Shin DY, Kang YH, Hwang N, Chung SW. Human retinal pigment epithelial cells express the long pentraxin PTX3. Mol Vis 2013; 19: 303-310.

29 Yang XF, Deng Y, Gu H, Lim A, Snellingen T, Liu XP et al. $\mathrm{C}$-reactive protein and diabetic retinopathy in Chinese patients with type 2 diabetes mellitus. Int J Ophthalmol 2016; 9: 111-118.

30 Cai XL, Wang F, Ji LN. Risk factors of diabetic retinopathy in type 2 diabetic patients. Chin Med J (Engl) 2006; 119: 822-826.

31 Klein BE, Knudtson MD, Tsai MY, Klein R. The relation of markers of inflammation and endothelial dysfunction to the prevalence and progression of diabetic retinopathy: Wisconsin epidemiologic study of diabetic retinopathy. Arch Ophthalmol 2009; 127: 1175-1182.

32 Funatsu H, Yamashita H, Noma H, Mimura T, Nakamura S, Sakata $\mathrm{K}$ et al. Aqueous humor levels of cytokines are related to vitreous levels and progression of diabetic retinopathy in diabetic patients. Graefes Arch Clin Exp Ophthalmol 2005; 243: 3-8.

33 Deban L, Russo RC, Sroni M, Moalli F, Scanziani M, Zambelli $\mathrm{V}$ et al. Regulation of leukocyte recruitment by the long pentraxin PTX3. Nat Immunol 2010; 11: 328-334.

34 Yang HS, Woo JE, Lee SJ, Park SH, Woo JM. Elevated plasma pentraxin 3 levels are associated with development and progression of diabetic retinopathy in Korean patients with type 2 diabetes mellitus. Invest Ophthalmol Vis Sci 2014; 55: 5989-5997.

35 Koleva-Georgieva DN, Sivkova NP, Terzieva D. Serum inflammatory cytokines IL-1beta, IL-6, TNF-alpha and VEGF have influence on the development of diabetic retinopathy. Folia Med (Plovdiv) 2011; 53: 44-50.

36 Maier R, Weger M, Haller-Schober EM, El-Shabrawi Y, Wedrich A, Theisl A et al. Multiplex bead analysis of vitreous and serum concentrations of inflammatory and proangiogenic factors in diabetic patients. Mol Vis 2008; 14: 637-643.

37 Adamiec-Mroczek J, Oficjalska-Młyńczak J, Misiuk-Hojło M. Roles of endothelin-1 and selected proinflammatory cytokines in the pathogenesis of proliferative diabetic retinopathy: Analysis of vitreous samples. Cytokine 2010; 49: 269-274.

38 Salcini C, Atasever-Arslan B, Sunter G, Gur H, Isik FB, Saylan CC et al. High Plasma Pentraxin 3 Levels in Diabetic Polyneuropathy Patients with Nociceptive Pain. Tohoku J Exp Med 2016; 239: 73-79.

39 Wang $\mathrm{R}$, Zhang J, Hu W. Association of serum pentraxin 3 concentrations with diabetic nephropathy. J Investig Med 2016; 64: 1124-1127.

40 Sun H, Tian J, Xian W, Xie T, Yang X. Pentraxin-3 attenuates renal damage in diabetic nephropathy by promoting M2 macrophage differentiation. Inflammation 2015; 38: 1739-1747. 